\section{Original} Article

\title{
Pathological Status of Mediastinal Lymph Nodes after Preoperative Concurrent Chemoradiotherapy Determines Prognosis in Patients with Non-Small Cell Lung Cancer
}

\author{
Yasushi Shintani, MD, PhD, ${ }^{1,2}$ Yasunobu Funakoshi, MD, PhD, ${ }^{3}$ Masayoshi Inoue, MD, PhD, ${ }^{1}$ \\ Yukiyasu Takeuchi, MD, PhD, ${ }^{3}$ Meinoshin Okumura, MD, $\mathrm{PhD},{ }^{1}$ \\ Hajime Maeda, MD, $\mathrm{PhD},{ }^{3}$ and Mitsunori Ohta, $\mathrm{MD}, \mathrm{PhD}^{2}$
}

\begin{abstract}
Objectives: The benefits of preoperative chemoradiotherapy for advanced nonsmall cell lung cancer (NSCLC) remain controversial. To evaluate prognostic indicators of clinical N2 NSCLC patients treated with concurrent chemotherapy followed by pulmonary resection, we performed a retrospective study.

Methods: We retrospectively investigated 52 patients with pathologically proven N2 NSCLC who underwent concurrent chemoradiotherapy before pulmonary resection. Each received 2 cycles of cisplatin-vinca alkaloid-based chemotherapy every 4 weeks. Radiotherapy, directed at the tumor and mediastinal nodes, was started on day 2 at a median dose of 44 Gy. A thoracotomy was performed 6 to 8 weeks after completion of chemoradiotherapy.

Results: The overall 5-year survival rate for the 52 patients was $38 \%$. Complete pathological response by the tumor was found in 11 (21\%). Down-staging of nodal stage occurred in 29 patients, $(\mathbf{5 6 \%})$ and overall survival was better in those with lower pathological $\mathrm{N}$ status. The 5-year survival rate was $58 \%$ for pathological N0-N1 disease and $0 \%$ for $\mathbf{N 2}$ disease. While the response to induction therapy by the primary tumor was correlated with postoperative nodal stage, multivariate analysis revealed postoperative nodal stage as an independent prognostic factor.
\end{abstract}

Conclusion: Pathological status of mediastinal lymph nodes in response to preoperative concurrent chemoradiotherapy determined prognosis in our patients.

Keywords: nonsmall cell lung cancer, preoperative concurrent chemoradiotherapy, prognostic indicator

\footnotetext{
${ }^{1}$ Department of General Thoracic Surgery, Osaka University Graduate School of Medicine, Suita, Osaka, Japan

${ }^{2}$ Department of General Thoracic Surgery, Osaka Prefectural Medical Center for Respiratory and Allergic Disease, Habikino, Osaka, Japan

${ }^{3}$ Department of General Thoracic Surgery, National Hospital Organization Toneyama Hospital, Toyonaka, Osaka, Japan
}

Received: October 13, 2011; Accepted: February 7, 2012

Corresponding author: Yasushi Shintani, MD, PhD. Department of General Thoracic Surgery, Osaka University Graduate School of Medicine, Suita, Osaka 565-0877, Japan

Email: yshintani@thoracic.med.osaka-u.ac.jp

(C)2012 The Editorial Committee of Annals of Thoracic and Cardiovascular Surgery. All rights reserved.

\section{Introduction}

The most effective treatment for patients with locally advanced nonsmall cell lung cancer (NSCLC) remains controversial. The results of surgical resection alone for locally advanced NSCLC are poor; thus the treatment option of induction chemoradiotherapy has been investigated. $^{1,2)}$ Although there is consensus about the indication for a multimodality approach in most patients with locally advanced disease, there is no clear agreement about which local therapy should be applied in a given situation. ${ }^{3)}$ Some reports have demonstrated that induction chemoradiotherapy followed by surgical resection 
provides better progression-free survival but not overall survival. ${ }^{4,5)}$ The purpose of this multi-institutional study was to evaluate prognostic indicators of clinical N2 NSCLC patients treated with concurrent chemoradiotherapy followed by pulmonary resection.

\section{Patients and Methods}

We investigated 52 patients with surgical resectable clinical N2 NSCLC who underwent preoperative concurrent chemoradiotherapy before pulmonary resection between 1995 and 2008 at Osaka Prefectural Medical Center for Respiratory and Allergic Disease, Toneyama National Hospital, and Osaka University Hospital. An institutional review board approved this retrospective study and written informed consent for surgical intervention was obtained from each patient. Patients were assessed by a thoracic surgeon, radiation oncologist, and medical oncologist to establish that the cancer was potentially technically resectable. Preoperative pathological N2 disease was shown by mediastinoscopy $(\mathrm{n}=35)$, perbronchial biopsy $(n=13)$, and thoracoscopy $(n=4)$ findings.

Patients received 2 cycles of chemotherapy every 4 weeks as follows: $\mathrm{PV}(\mathrm{M})$ regimen, cisplatin $80 \mathrm{mg} / \mathrm{m}^{2}$ on day 1 and vindesine $3 \mathrm{mg} / \mathrm{m}^{2}$ on days 1 and 8 with or without mitomycin $8 \mathrm{mg} / \mathrm{m}^{2}$ on day 1 according to the protocol of Japan Clinical Oncology Group 9209 and 9806 ${ }^{6,7)}$; nPV regimen, cisplatin $80 \mathrm{mg} / \mathrm{m}^{2}$ on day 1 and vinorelbine $20 \mathrm{mg} / \mathrm{m}^{2}$ on days 1 and 8 every 4 weeks according to the protocol described by Naito et al. ${ }^{8}$ Radiotherapy directed at the tumor and mediastinal nodes was started on day 2 concurrently in cycle 1 and the total radiation dose was $40 \mathrm{~Gy}$ in 20 fractions administered over 4 weeks. For poor responding patients $(\mathrm{n}=10)$, an additional dose of 10 to $20 \mathrm{~Gy}$ was administered. Following induction chemoradiotherapy, each case was reevaluated to determine clinical response and indications for resection. A thoracotomy was performed in all patients 6 to 8 weeks after completion of chemoradiotherapy. The surgical procedures included a lobectomy or pneumonectomy with systemic node dissection.

A chi-square test was used to compare the results. Overall survival rates were estimated by the method of Kaplan and Meier, and compared with results of a logrank test. All patient characteristics were tested multivariately against the primary outcome using a Cox-regression analysis based on the tested variable. All statistical analyses were performed using Statview version 5.0 for Windows (Abacus Concepts, Berkeley, CA). A p-value of
Table 1 Patient Characteristics $(n=52)$

\begin{tabular}{lc}
\hline Characteristics & No. of patients \\
\hline Gender & \\
Male & 43 \\
Female & 9 \\
Clinical stage & \\
IIIA & 40 \\
IIIB & 12 \\
Clinical T stage & \\
T1 & 5 \\
T2 & 27 \\
T3 & 8 \\
T4 & 12 \\
Clinical N stage & \\
N2 & 52 \\
Histology & \\
Adenocarcinoma & 34 \\
Squamous cell carcinoma & 15 \\
Others & 3 \\
Type of mediastinal staging & \\
$\quad$ Mediastinoscopy & 35 \\
$\quad$ Perbronchial biopsy & 13 \\
$\quad$ Thoracoscopy & 4 \\
\hline$\quad$
\end{tabular}

$<0.05$ was considered to be statistically significant.

\section{Results}

The median patient age was 57 years old (range 32-73 years), and their clinicopathologic characteristics are shown in Table 1. The median radiation dose was $44 \mathrm{~Gy}$ (30-60 Gy), and data for preoperative treatments and surgical procedures are presented in Table 2. The overall cardiopulmonary morbidity, early mortality, and 90-day mortality rates were $38 \%(n=20), 3.8 \%(n=2)$, and $7.6 \%$ $(\mathrm{n}=4)$, respectively. Postoperative cardiopulmonary morbidity rate was not associated with type of chemotherapy (CDDP + VDS vs. CDDP + VDS + MMC vs. CDDP + VNR; morbidity rate $47 \%$ vs. $45 \%$ vs. $22 \%$; $p=0.38$ ) or radiation dose ( $40 \mathrm{~Gy} \geq$ vs. $40 \mathrm{~Gy}<; 46 \%$ vs $30 \%$; $\mathrm{p}=$ 0.36 ), while it was greater in patients who underwent a pneumonectomy than in those who underwent a lobectomy $(73 \%$ vs. $29 \%, \mathrm{p}=0.01)$.

Twenty-one patients were alive after a median followup period of 4.8 years, and the overall 5-year survival rate was $38 \%$ (Fig. 1A). Complete pathological response by the tumor was found in 11 patients (21\%, see Table 3A), though there was no significant difference in survival rate according to tumor pathological response [Complete pathological response (CR-tumor) vs. Non-complete pathological response (NCR-tumor), $p=0.07$, Fig. 1B). 
Table 2 Preoperative treatment and surgical procedures, and results

\begin{tabular}{|c|c|}
\hline Procedure/Result & No. of patients \\
\hline \multicolumn{2}{|l|}{ Chemotherapy } \\
\hline CDDP + VDS & 31 \\
\hline $\mathrm{CDDP}+\mathrm{VDS}+\mathrm{MMC}$ & 12 \\
\hline $\mathrm{CDDP}+\mathrm{VNR}$ & 9 \\
\hline \multicolumn{2}{|l|}{ Radiation dose } \\
\hline $40 \mathrm{~Gy} \geq$ & 40 \\
\hline $40 \mathrm{~Gy}<$ & 12 \\
\hline \multicolumn{2}{|l|}{ Surgical procedure } \\
\hline Lobectomy & 43 \\
\hline Pneumonectomy & 9 \\
\hline \multicolumn{2}{|l|}{ With combined resection } \\
\hline Bronchoplasty & 8 \\
\hline $\mathrm{Rib}$ & 4 \\
\hline Pericardium & 4 \\
\hline Major vessel & 2 \\
\hline Diaphragma & 2 \\
\hline \multicolumn{2}{|l|}{ Morbidity } \\
\hline None & 32 \\
\hline Pneumonia & 7 \\
\hline (ARDS & 2) \\
\hline (Radiation pneumonitis & 2) \\
\hline Atelectasis & 4 \\
\hline Empyema & 4 \\
\hline (Broncho-fistula & $2)$ \\
\hline Chylothorax & 2 \\
\hline Arrythmia & 5 \\
\hline Heart failure & 2 \\
\hline Mortality & 3 \\
\hline ARDS & 2 \\
\hline Hemoptysis & 1 \\
\hline
\end{tabular}

CDDP: cisplatin; VDS: vindesine; MMC: mitomycin; VNR: vinorelbine ARDS: adult respiratory distress syndrome

Pathological N0-1 status was found in 29 patients, (56\%) and overall survival was better in those with a lower $\mathrm{p}-\mathrm{N}$ status (Pathological N0-1 status vs. N2 status, $\mathrm{p}=0.005$, Fig. 1C), as the 5-year survival rate was 58\% in patients with stage p-N0-1 disease and $0 \%$ in those with p-N2 disease. Overall survival did not differ according to the surgical procedure employed (lobectomy vs. pneumonectomy, $\mathrm{p}=0.74$ ).

Response to induction therapy by the primary tumor was correlated with postoperative nodal stage $(\mathrm{p}=0.01$, Table 3B). Only one patient with CR-tumor belonged to p-N2 group. The 5-year survival rate was $90 \%$ in patients with CR-tumor and p-N0-1 disease, $51 \%$ in those with NCR-tumor and p-N0-1 disease, and 0\% in those with NCR-tumor and p-N2 disease. In univariate analysis, postoperative nodal stage was a prognostic factor (Table 3C). Two variables, including tumor response to
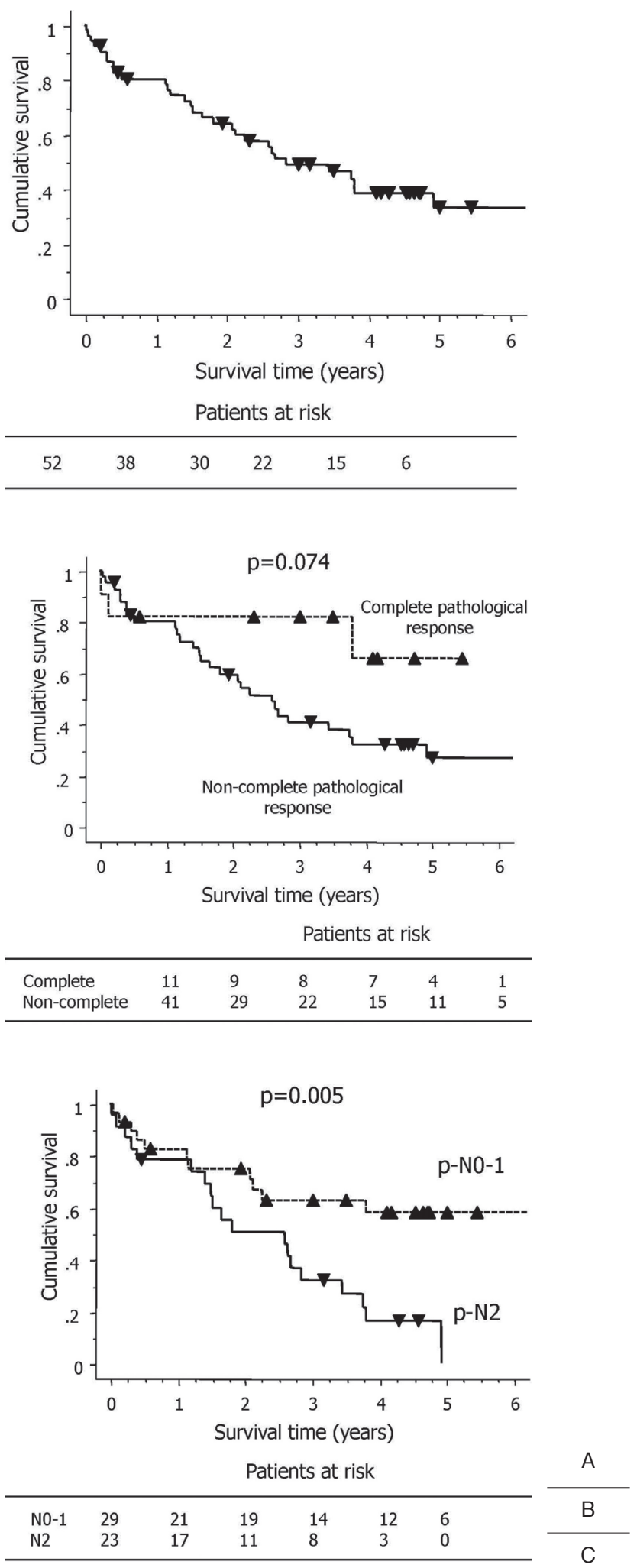

Fig. 1

A: Overall survival for all cases $(n=52)$.

B: Overall survival according to pathological response of the tumor.

C: Overall survival according to pathological nodal status after chemoradiotherapy. 
Table 3

A. Postoperative pathologic results

\begin{tabular}{lc}
\hline Characteristics & No. of patients \\
\hline Pathologic T stage & \\
T0* & 11 \\
T1 & 16 \\
T2 & 18 \\
T3 & 6 \\
T4 & 1 \\
Pathologic N stage & \\
N0 & 25 \\
N1 & 4 \\
N2 & 23 \\
\hline T0, pathological complete response in primary tumor
\end{tabular}

*T0, pathological complete response in primary tumor

B. Postoperative pathologic response in tumor and lymph nodes

\begin{tabular}{lcc}
\hline \multirow{2}{*}{$\begin{array}{l}\text { Pathologic response } \\
\text { in tumor }\end{array}$} & \multicolumn{2}{c}{$\mathrm{N}$ status } \\
\cline { 2 - 3 } Complete & $\mathrm{p}-\mathrm{N} 0-1$ & $\mathrm{p}-\mathrm{N} 2$ \\
Non-complete & 10 & 1 \\
\hline *T0, pathological complete response; $\mathrm{p}=0.01$, chi- \\
square test
\end{tabular}

CRT and postoperative nodal stage which were correlated with each other, were analyzed to determine the variables having an effect on survival in NSCLC patients (Table 3D). The analysis revealed that postoperative nodal stage was an independent prognostic factor.

\section{Discussion}

Cisplatin-vinca alkaloid-based chemotherapy combined with radiation was administered in the present cases, which has been reported to be the most popular and well-tolerated combination for NSCLC in Japan. ${ }^{6-8)}$ We previously used cisplatin and vindesine in the 1990s, and then changed vindesine to vinorelbine in the 2000s. Chemotherapy regimens with new agents, including paclitaxel, docetaxel, and gemcitabine, have recently been reported to be effective for advanced NSCLC., ${ }^{910)}$ These new agents combined with radiotherapy may also improve overall long-term survival by inducing an increased pathological response by the tumor to induction therapy in patients with local, advanced NSCLC. ${ }^{11)}$

Similar to the German Lung Cancer Cooperative Group (GLCCG) trial, ${ }^{5)}$ we found that preoperative concurrent chemoradiotherapy increased pathological response and mediastinal down-staging, while multivariate
C. Univariate analysis of prognostic factors

\begin{tabular}{lcc}
\hline Variable & $\begin{array}{c}\text { Hazard ratio } \\
(95 \% \mathrm{CI})\end{array}$ & $\mathrm{p}$ value \\
\hline $\begin{array}{l}\text { Tumor response } \\
\quad \text { Non-complete vs. complete }\end{array}$ & $3.40(0.81-14.3)$ & 0.09 \\
$\begin{array}{l}\text { p-N status } \\
\text { N2 vs N0-1 }\end{array}$ & $2.81(1.29-6.11)$ & 0.01 \\
\hline
\end{tabular}

\section{Multivariate analysis of prognostic factors}

\begin{tabular}{lcc}
\hline Variable & $\begin{array}{c}\text { Hazard ratio } \\
(95 \% \mathrm{CI})\end{array}$ & $\mathrm{p}$ value \\
\hline $\begin{array}{l}\text { Tumor response } \\
\quad \begin{array}{l}\text { Non-complete vs. complete } \\
\text { p-N status } \\
\mathrm{N} 2 \text { vs N0-1 }\end{array}\end{array}$ & $1.68(0.44-6.35)$ & 0.444 \\
\hline
\end{tabular}

analysis showed that pathological $\mathrm{N}$ status was an independent predictor of survival. These results suggest that new methods for achieving better control of mediastinal lymph node involvement are needed to improve the overall outcome for patients with locally advanced NSCLC. Along that line, we believe that it is important to accurately select patients in whom preoperative $\mathrm{N} 2$ or N3 disease will be controlled by induction chemoradiotherapy for improvement of long-term survival with trimodality therapy. Since N2 disease after chemoradiotherapy has a negative prognostic significance, nodal status should be assessed after induction chemoradiotherapy using computed tomography (CT) and ${ }^{18} \mathrm{~F}$-fluorodeoxy glucose-positron emission tomography (FDG-PET) examinations. When apparent $\mathrm{N} 2$ disease is confirmed even after induction chemoradiation, it may be best to avoid a pulmonary resection and treat the patient with definitive chemoradiotherapy. In addition, aggressive staging with EBUSTBNA as well as a re-mediastinoscopy can be performed, in addition to conventional examinations to exclude such patients from surgical resection. ${ }^{12-14)}$ On the other hand, response to induction therapy by the primary tumor was shown to be correlated with postoperative down-staging of mediastinal nodes in the present study; thus it is necessary to evaluate using CT or FDG-PET to monitor 
treatment response by the primary tumor after induction chemoradiotherapy and predict down-staging of mediastinal nodes. The value of FDG-PET for the primary tumor and its response to therapy should be evaluated in a future study.

The most commonly used dose for induction therapy ranges from 40 to $45 \mathrm{~Gy}^{2,8)}$ Sonett et al. reported that high dose radiation promotes a high pathologically complete response rate and pulmonary resection may be performed safely after CRT including greater than $59 \mathrm{~Gy}$ radiotherapy. ${ }^{11)}$ In our series, 6 patients received $60 \mathrm{~Gy}$ radiotherapy as CRT and each safely underwent pulmonary resection.

The type of surgery is also a determinant of morbidity and mortality. Albain and colleagues recently reported significantly higher mortality rates with a pneumonectomy $(26 \%)$ as compared to a lobectomy (1\%); thus no survival difference was found between the surgical and non-surgical arms in their study, ${ }^{15)}$ because the increased mortality in patients who required a pneumonectomy after induction chemoradiotherapy adversely affected the overall survival of the surgical group. However, some reports have shown that induction chemoradiotherapy does not increase the risk of morbidity and mortality after a pneumonectomy in properly selected patients. ${ }^{3,15)}$ In the present study, there was no significant difference for 90 day mortality and overall survival between patients who underwent a pneumonectomy and those who received a lobectomy, whereas cardiopulmonary morbidity and early mortality rates were greater in patients with a pneumonectomy than those with a lobectomy. Notably, a right pneumonectomy after chemoradiotherapy has been reported to be associated with relatively increased risk and should be performed only in selected patients. ${ }^{16)}$

Our study has some potential limitations, as it was an observational study performed at 3 different centers and not a randomized trial. Therefore, multicenter prospective randomized trials in Japan are needed for accurate investigation of the effects and risks of trimodality treatment in patients with NSCLC.

\section{Conclusion}

Pathological response by mediastinal lymph nodes to preoperative concurrent chemoradiotherapy determined the prognosis in our patients with N2 NSCLC.

\section{Acknowledgment}

We thank Dr Yuko Ohno (professor of Department of Mathematical Health Science, Osaka University Graduate School of Medicine) for her assistance on some statistical work.

\section{References}

1) Friedel G, Budach W, Dippon J, et al. Phase II trial of a trimodality regimen for stage III non-small-cell lung cancer using chemotherapy as induction treatment with concurrent hyperfractionated chemoradiation with carboplatin and paclitaxel followed by subsequent resection: a single-center study. J Clin Oncol 2010; 28: 942-8.

2) Uy KL, Darling G, Xu W, et al. Improved results of induction chemoradiation before surgical intervention for selected patients with stage IIIA-N2 non-small cell lung cancer. J Thorac Cardiovasc Surg 2007; 134: 18893.

3) Weder W, Collaud S, Eberhardt WE, et al. Pneumonectomy is a valuable treatment option after neoadjuvant therapy for stage III non-small-cell lung cancer. J Thorac Cardiovasc Surg 2010; 139: 1424-30.

4) Gilligan D, Nicolson M, Smith I, et al. Preoperative chemotherapy in patients with resectable non-small cell lung cancer: results of the MRC LU22/NVALT 2/ EORTC 08012 multicentre randomised trial and update of systematic review. Lancet 2007; 369: 1929-37.

5) Thomas M, Rübe C, Hoffknecht P, et al. Effect of preoperative chemoradiation in addition to preoperative chemotherapy: a randomised trial in stage III nonsmall-cell lung cancer. Lancet Oncol 2008; 9: 636-48.

6) Nagai K, Tsuchiya R, Mori T, et al. A randomized trial comparing induction chemotherapy followed by surgery with surgery alone for patients with stage IIIA N2 non-small cell lung cancer (JCOG 9209). J Thorac Cardiovasc Surg 2003; 125: 254-60.

7) Kunitoh H, Kato H, Tsuboi M, et al. Phase II trial of preoperative chemoradiotherapy followed by surgical resection in patients with superior sulcus non-smallcell lung cancers: report of Japan Clinical Oncology Group trial 9806. J Clin Oncol 2008; 26: 644-9.

8) Naito Y, Kubota K, Nihei K, et al. Concurrent chemoradiotherapy with cisplatin and vinorelbine for stage III non-small cell lung cancer. J Thorac Oncol 2008; 3: 617-22.

9) Pectasides D, Kalofonos HP, Samantas E, et al. An out-patient second-line chemotherapy with gemcitabine and vinorelbine in patients with non-small cell lung cancer previously treated with cisplatin-based chemotherapy. A phase II study of the Hellenic co-operative Oncology Group. Anticancer Res 2001; 21: 3005-10.

10) Sandler AB, Nemunaitis J, Denham C, et al. Phase III 
trial of gemcitabine plus cisplatin versus cisplatin alone in patients with locally advanced or metastatic non-small-cell lung cancer. J Clin Oncol 2000; 18: 122-30.

11) Sonett JR, Suntharalingam M, Edelman MJ, et al. Pulmonary resection after curative intent radiotherapy (>59 Gy) and concurrent chemotherapy in non-smallcell lung cancer. Ann Thorac Surg 2004; 78: 1200-5.

12) Surmont V, van Klaveren RJ, Goor C, et al. Lessons to learn from EORTC study 08981: a feasibility study of induction chemoradiotherapy followed by surgical resection for stage IIIB non-small cell lung cancer. Lung Cancer. 2007; 55: 95-9.

13) Ryu JS, Choi NC, Fischman AJ, et al. FDG-PET in staging and restaging non-small cell lung cancer after neoadjuvant chemoradiotherapy: correlation with histopathology. Lung Cancer 2002; 33: 179-87.

14) Albain KS, Swann RS, Rusch VW, et al. Radiotherapy plus chemotherapy with or without surgical resection for stage III non-small-cell lung cancer: a phase III randomised controlled trial. Lancet 2009; 374: 379-86.

15) Refai M, Brunelli A, Rocco G, et al. Does induction treatment increase the risk of morbidity and mortality after pneumonectomy? A multicentre case-matched analysis. Eur J Cardiothorac Surg 2010; 37: 535-9.

16) Martin J, Ginsberg RJ, Abolhoda A, et al. Morbidity and mortality after neoadjuvant therapy for lung cancer: the risks of right pneumonectomy. Ann Thorac Surg 2001; 72: 1149-54. 